\title{
Associations between Workplace Characteristics and "Outness" in LGBTI Workers in
}

\section{Austria}

Lovro Markovic $^{1,2^{*}}$, Daniel Schönherr ${ }^{3}$, Martina Zandonella ${ }^{3}$, Alejandro Gil-Salmeron ${ }^{4}$, Lee Smith ${ }^{5}$, Daragh T. McDermott ${ }^{6}$, Lin Yang ${ }^{7,8}$, Thomas E Dorner ${ }^{1,9}$, Hanna M Mües ${ }^{10}$, Igor Grabovac ${ }^{1}$

${ }^{1}$ Department of Social and Preventive Medicine, Centre for Public Health, Medical University of Vienna, Kinderspitalgasse 15, 1090 Vienna, Austria

${ }^{2}$ Department of Physical Medicine, Rehabilitation and Occupational Medicine, Medical University of Vienna, Währinger Gürtel 18-20, 1090 Vienna, Austria

${ }^{3}$ SORA Institute for Social Research and Consulting, Ogris \& Hofinger GmbH, Bennogasse 8/2/16, 1080 Vienna, Austria

${ }^{4}$ International Foundation for Integrated Care, Annex offices, Linton Rd, Oxford, OX26UD, United Kingdom

${ }^{5}$ Cambridge Centre for Sport and Exercise Sciences, Anglia Ruskin University, Cambridge, United Kingdom

${ }^{6}$ Department of Psychology, School of Social Sciences, Nottingham Trent University, 50 Shakespeare Street, Nottingham, United Kingdom

${ }^{7}$ Department of Cancer Epidemiology and Prevention Research, Cancer Care Alberta, Alberta Health Services, Calgary, Alberta, Canada

${ }^{8}$ Departments of Oncology \& Community Health Sciences, Cumming School of Medicine, University of Calgary, Hospital Drive NW, Calgary, Alberta, Canada

${ }^{9}$ Social Insurance Fund for Public Service, Railway and Mining Industries, Health Promotion Facility Sitzenberg-Reidling, 3454 Sitzenberg-Reidling, Austria

${ }^{10}$ Department of Clinical and Health Psychology, Faculty of Psychology, University of Vienna, Vienna, Austria 
*Corresponding author's address and contact details:

Lovro Markovic

Department of Physical Medicine, Rehabilitation and Occupational Medicine

Medical University of Vienna

Währinger Gürtel 18-20

1090 Vienna, Austria

Email: lovro.markovic@meduniwien.ac.at

Tel: +4314040043300 


\begin{abstract}
Objectives

Lesbian, gay, bisexual, transgender and intersex (LGBTI) individuals are often subjected to negative attitudes in the workplace, which may lead to non-disclosure of their sexual orientation and/or gender identities. We aimed to determine the prevalence of workplace disclosure of sexual or gender identity (i.e., "outness"; being "out") and to examine its associations with workplace characteristics in LGBTI workers in Austria.
\end{abstract}

\title{
Methods
}

This cross-sectional study analyzed sociodemographic, work- and wellbeing-related data from self-identifying gender- and/or sexual minority participants elicited by an online questionnaire between February and June 2017. From the initial 1268 respondents, 1177 (93\%) provided complete data and were included in the subsequent analyses.

\section{Results}

The largest proportion of the sample were 26-35 years old (39.1\%), cisgender gay men (40.0\%) in full-time employment (63.9\%). Overall, $51.7 \%$ of the sample were "out" at the workplace. Being bisexual $(\mathrm{OR}=0.46,95 \% \mathrm{CI} 0.27-0.81)$, the provision of anti-discrimination guidelines in the workplace $(\mathrm{OR}=0.53,95 \% \mathrm{CI} 0.32-0.90)$, living alone $(\mathrm{OR}=0.50,95 \% \mathrm{CI} 0.32-0.79)$ and in shared households $(\mathrm{OR}=0.49,95 \% \mathrm{CI} 0.25-0.96)$ were associated with a decreased likelihood of being "out" at work.

Factors associated with being "out" at work were being middle aged (36-45-year-olds; $\mathrm{OR}=1.74,95 \% \mathrm{CI} 1.07-2.85)$, having been in employment for $>10$ years $(\mathrm{OR}=2.03,95 \% \mathrm{CI}$ 1.08-3.81), a LGBTI-friendly work environment (OR 1.61, 95\%CI 1.36-1.91), labor- 
management anti-discrimination contract $(\mathrm{OR}=2.02,95 \% \mathrm{CI} 1.23-3.32)$, and work council protections $(\mathrm{OR}=1.56,95 \% \mathrm{CI} 1.04-2.36)$.

\section{Conclusions}

Instating anti-discrimination protections might facilitate "outness" of LGBTI workers and lead to a better promotion of diversity in the workplace.

\section{Keywords}

labour policy; sexual orientation; gender identity; workplace characteristics; workplace guideline; workplace health; workplace relations

\section{Key messages}

What is already known about this subject?

- A high proportion of LGBTI people experience discrimination in the workplace, and as a consequence conceal their sexual orientation and/or gender identity

- Lower workplace outness is associated with decreased job satisfaction, poorer health and work-related outcomes

What are the new findings?

- Data from 1177 participants were analyzed concerning workplace characteristics and outness for the first time in Austria

- Only half of surveyed participants were out about their sexual orientation and/or gender identity in the workplace

- Workers who were middle-aged, employed for more than 10 years, worked in a LGBTIfriendly environment, enjoyed legally binding anti-discrimination and work council protections were more likely to be out at work 
How might this impact on policy or clinical practice in the foreseeable future?

- Policymakers should include legally binding anti-discrimination measures specifically targeting the LGBTI working population

- Creating inclusive workplaces where people are able to be open about their sexual orientation and gender identity may increase productivity and improve health outcomes 


\section{Introduction}

Despite the improving legal situation and a more egalitarian societal climate in many countries ${ }^{1-4}$ discrimination of lesbian, gay, bisexual, transgender and intersex (LGBTI) people persists with $58 \%$ of sexual and gender minority Europeans reporting experiences of discrimination in daily life ${ }^{3}$. LGBTI individuals are often confronted with people and workplace structures that condone negative attitudes in the workplace ${ }^{5}$. A recent report by the Fundamental Rights Agency (FRA) of the European Union showed that 1 in 4 LGBTI individuals hide their identity at work, with 1 in 5 saying they felt discriminated against in the workplace ${ }^{3}$.

Discrimination of LGBTI workers may not always be overt ${ }^{6}$, and can have a range of consequences such as conflict with co-workers, career development problems, or economic inequity. Furthermore, LGBTI workers are exposed to hetero- and cis-normative work culture, meaning that being heterosexual and having a cisgender identity (i.e., that biological sex matches gender identity) are assumed applicable to all workers ${ }^{7}$. This creates further specific challenges where LGBTI workers may feel pressured to not disclose their identity or to "stay in the closet"8. For transgender people the assumption of cis-normativity may enforce stereotypical binary gender roles pressuring them to present as and perform gender roles based on their sex as assigned at birth, rather than their affirmed gender 9 .

Workers often 'come out' (i.e. disclose sexual or gender identity) to certain individuals at work and choose the extent to which they openly disclose their identity as a continuous process ${ }^{10}$. Hetero- and cis-normative working environments may lead to non-disclosure of sexual and gender identity, especially where discrimination goes unreported or unsanctioned. Extant literature demonstrates that less workplace outness ${ }^{11}$ is associated with decreased job satisfaction $^{12}{ }^{13}$, poorer health (i.e., lower well-being and increased depressive symptoms ${ }^{14}$ ) 
and work-related outcomes (such as lower productivity ${ }^{15}$ ). The potential for negative consequences may be the main reason why LGBTI workers choose not to disclose their identity ${ }^{16}$. Conversely, outness at work is associated with reductions in workplace discrimination $^{3}$ as well with improved job satisfaction, workplace commitment ${ }^{17}$ and improved productivity of the whole work collective ${ }^{18}$.

In Austria, legal protections for LGBTI individuals have been advancing and various reports indicate rising societal support for LGBTI equality ${ }^{3416}$. However, there is a paucity of studies examining the LGBTI working population, with one 2015 report indicating that $48 \%$ of LGBTI people in Vienna are not open about their sexual orientation in the workplace ${ }^{19}$, however this lacked any data on workplace characteristics or environment.

The majority of the literature concerning LGBTI workers focuses on economic and corporate outcomes, as well as productivity ${ }^{172021}$, overshadowing implications of workplace characteristics on workers' outness. However, results from few available studies highlight the importance of workplace characteristics that influence the level of outness of LGBTI workers ${ }^{7}$. For example, studies indicated that implementation of non-discrimination and supportive policies facilitate outness in LGBTI workers ${ }^{22}$ but also lower discrimination, improve mental health outcomes, and positively affect performance at work ${ }^{23}$. However, there is a considerable paucity of studies investigating workplace outness and experiences of LGBTI workers. Therefore, we aimed to determine the prevalence of workplace outness among LGBTI workers in Austria and the associated workplace characteristics. To the best of our knowledge this is the first such study from Central Europe.

\section{Methods}

A cross-sectional study using an online-based questionnaire was conducted between February and June 2017. The study link was distributed among various LGBTI organizations 
in Austria, and the participants were asked to disseminate the link among their own networks. The study was commissioned by the Vienna Chamber of Labour, who examined and approved the questionnaire and methodology. Given that this paper presents a secondary analysis of data, no other ethical approval was sought. Participants were anonymous, with no personal information being asked, as well as no email or IP addresses being saved. Participation was voluntary and was conducted in accordance with the Helsinki declaration in its current revision.

\section{Study population}

Participants between 16 and 65 years of age, residing in Austria, who were in paid employment and self-identify as a gender- and/or sexual minority were included in the study.

\section{Questionnaire}

Overall, the questionnaire consisted of 50 questions, which were multiple and single choice and were specifically designed for this study. The questionnaire addressed, outness at the workplace, sociodemographic characteristics, workplace characteristics, and protections against discrimination at the workplace and took roughly 10 minutes to complete.

\section{Outness at the workplace}

Outness at the workplace was determined using the question "Are you "out" as LGBTI when it comes to the following persons in your private and professional environment: immediate colleagues, other coworkers, superiors, and clients". For each category, participants could choose from a Likert type scale (1-5) including (1) Yes, with all; (2) Yes, with most; (3) Yes, with some; (4) No, and (5) Not applicable. Participants (n=16) who chose "not applicable" across all categories or did not disclose any information about their outness status at the workplace were excluded from analysis. We calculated a score based on the outcomes and dichotomized the workplace outness based on a median split, with lower scores indicating higher degrees of outness. 


\section{Covariates}

\section{Sexual- and gender identity}

Sexual- and gender identity were ascertained with the following two questions; "How would you describe your sexual orientation?" (1) Gay; (2) Lesbian; (3) Bisexual; (4) Heterosexual; (5) Other (please note); (6) I don't want to assign myself, and "How do you define your sex or gender self-image?" (1) born as a woman and living as a woman; (2) born as a man and living as a man; (3) born as a man and living as a woman; (4) born as a woman and living as a man; (5) born intersexual and living as a man; (6) born intersexual and living as a woman; (7) born intersexual and living neither as a woman nor as a man; (8) other; (9) I don't want to assign myself.

\section{$\underline{\text { Sociodemographic characteristics }}$}

Eight questions concerned age, citizenship, migration background, level of education (based on the International Standard Classification of Education, ISCED), living situation, and postal code (to determine the degree of urbanization based on DEGURBA classification), and overall life and work satisfaction (based on agreement with the statements "I am very satisfied with my life as it is now" and "I am happy at my work" on a 1-4 scale; $1=$ "does not apply at all" and 4="applies fully").

\section{$\underline{\text { Workplace characteristics }}$}

Thirteen questions elicited participants' employment status, working hours, type of employment contract and position level, monthly income from work, employment sector, company size, duration of employment, perceived job security (based on the question "Do you consider your job as..." with $1=$ "very insecure" and 4="very secure"), general perceived attitude towards LGBTI persons at the workplace (based on agreement with the statement "How would you assess the general mood and attitude towards LGBTI people and LGBTI 
issues at your workplace/work location?" on a 1-7 scale; $1=$ "very negative" and 7="very positive”), and presence of LGBTI supervisors and colleagues.

\section{Discrimination protections at the workplace}

A further eight questions on discrimination protections at the workplace were included, such as the presence of guidelines for dealing with LGBTI, presence of a workers' council (and whether LGBTI interests are represented therein), presence of a diversity representative, presence of a trusted person at work, presence of labor-management contracts to prevent LGBTI-based discrimination, presence of support for LGBTI-networking within the company, and presence of targeted diversity management.

\section{Statistical analysis}

Descriptive analyses included means and standard deviation for metric variables, and categorical variables are presented as frequencies and percentages. To assess differences between workers who were categorized as out at work and those who were not, we used $t$-test and Mann-Whitney-U test, depending on data distribution with Chi-square test being used for differences in categorical variables.

We performed a multivariable logistic regression model (mutually adjusted, listwise exclusion of cases) to assess which worker and workplace characteristics were associated with workplace outness. Variables in the model were chosen based on the univariate analysis using the cutoff point of $\mathrm{p}<0.2^{24}$, with the largest group chosen as the reference in the model. Statistical analyses were done using SPSS for Windows v26.0, all tests were two tailed, with $p$-values less than 0.05 denoting statistical significance.

\section{Results}

Sample characteristics 
A total of 1268 individuals participated in the study. Cases were excluded if data on sexual orientation or gender identity were missing or if there were more than $50 \%$ missing entries. Overall, 1177 (93\%) participants were included in our analysis with 51.6\% $(n=608)$ reporting being out at the workplace. Descriptive characteristics of the study sample and differences based on outness at the workplace are shown in Table 1. Most participants were sexual minority and cisgender $(68.6 \% ; n=808)$ young adults $(39.1 \% ; 26-35$ years old $)$, had tertiary level education (43.9\%), were living with a partner (35.9\%), had full-time employment (63.9\%), held their current position for less than 3 years (44.3\%), had LGBTI coworkers (56.5\%), but no outed LGBTI superiors (69.2\%), with the overall job perception as "safe" $(M$ $=3.15)$ and their work environment as LGBTI-friendly $(M=5.14$; SD 1.45).

Factors associated with outness: univariate analysis

The univariate analysis revealed significant differences between participants who were out at work and those who were not with respect to the following variables (Table 1): sexual and gender identity, age, migration background, living situation, managing responsibility, company size, duration of employment at current workplace, perceived job stability, perceived workplace LGBTI friendliness, happiness in life, happiness at work, having LGBTI coworkers or superiors, having a labor-management anti-discrimination contract, targeted diversity management, and worker council protections.

Factors associated with outness: multivariate regression model

Associations between workplace outness, workplace and sociodemographic characteristics are presented in Table 2. Participants who self-identified as bisexual were 2.17 times more likely to conceal their sexual orientation or gender identity at work. Presence of anti-discrimination guidelines in the workplace was associated with two times lower likelihood 
of being out at work. Those who reported living alone or living in shared accommodations were also two times less likely to be out at work.

Participants who were working for more than 10 years at the same workplace, middleaged workers (35-50) had higher odds to be out at the workplace. Workplace characteristics significantly associated with higher likelihoods of workplace outness were: perceived LGBTI friendliness, having a workers' council and a labor management anti-discrimination contract (Table 2).

\section{Discussion}

Our study explored workplace and workers`characteristics and their associations with being out in the workplace among a sample of LGBTI workers in Austria. Overall, 1177 workers were analyzed with half of our participants reporting being out in the workplace. In our model we found higher likelihoods of outness at work among workers aged 36-50, who had worked for more than 10 years at the same workplace, that positively perceived LGBTI workplace friendliness, had a presence of work council protections, and a labor-management anti-discrimination contract. The opposite was found for those who identified as bisexual, had anti-discrimination guidelines at work, were living alone, or in shared households without a partner (Table 2).

There is a lack of literature examining the prevalence of workplace outness and workplace characteristics. However, a recent report by FRA stated that EU-wide around 26\% of participants hid their sexual orientation at work ${ }^{3}$. A study by Lloren and Parini in a Swiss sample or LGBTI workers reported overall outness of $87 \%{ }^{25}$, with only $42 \%$ of workers being out to everyone. The difference in the reported prevalence of workplace outness most likely stems from the way outness was conceptualized and measured in our respective studies. 
Our sample included 808 (68.6\%) gay lesbian participants and $221(18.8 \%)$ bisexual respondents who were more frequently identified as "not out" (13.5\% vs $24.4 \%)$ and were found to be 2.17 times more likely to conceal their identity at the workplace. These findings are consistent with other studies 102627 . Bisexual individuals are widely exposed to both biphobia and homophobia, leading to a unique form of minority stress in bisexual individuals 28. Bisexual people thus face double stigmatization by being discriminated not only by the heterosexual majority but also by other sexual minorities ${ }^{28}$ often by denying the existence or legitimacy of a bisexual identity ${ }^{29}$ or being ascribed bi-negative stereotypes such as being untrustworthy or promiscuous ${ }^{30}$. Such attitudes seem to stem most from non-bisexual men ${ }^{29}$ 31. Due to these circumstances, bisexual employees are often silenced or invisible due to discrimination from other sexual minorities but also the heterosexual majority ${ }^{2628}$, which may lead to internalized biphobia ${ }^{27}$ that appears to be more detrimental if associated with discrimination from gay and lesbian peers ${ }^{32}$. In order to increase the level of outness at workplaces it is important to acknowledge the double stigma experienced by bisexual employees by actively increasing awareness of bisexual identities and their explicit inclusivity in anti-discriminatory policies, in turn leading to higher levels of perceived safety ${ }^{33}$.

Even though gender minority groups share some discriminatory experiences with sexual minority groups, they are likely to be faced with distinct and unique challenges in the workplace ${ }^{34}$. There is a general lack of studies specifically examining non-cis gender participants of the workforce ${ }^{36}$, possibly due to the relatively lower visibility under the LGBTI identity umbrella. However, the second EU-wide LGBTI survey in 2019 showed a rise in perceived workplace discrimination in trans-respondents (36\%) compared to the first survey in $2012(22 \%)$, whereas the rise was notably lower for lesbian, gay, and bisexual respondents $(21 \% \text { vs. } 19 \%)^{316}$. Transgender workers made up $7.5 \%$ of our study sample with differences among sexual orientation and gender identity groups being significant vis-à-vis workplace 
outness, however a non-cis gender identity was not found to be significantly associated with workplace outness in the regression model. Moreover, in absolute numbers, trans and intersex respondents were more commonly out $(9.7 \%, \mathrm{n}=59)$ than not $(5.1 \%, \mathrm{n}=29)$. The long and complicated process of gender transitioning and recognition (including medical, social, and legal procedures) might force non cis-gender workers to come out at work, which combined with social and legal identity recognition issues might lead to greater vulnerability. It has been reported that trans-employees face more physical violence in the workplace than sexual minority employees ${ }^{9}$. Even though Austrian and EU law prohibits workplace discrimination based on gender identity, these protections lose their meaning when one is unable to legally change the gender assigned to them at birth. Negative consequences of "forced" outing in trans workers could be improved by targeted anti-discrimination measures and wider legal change.

Interestingly, our results also showed that the presence of anti-discrimination guidelines at the workplace was associated with less outness. Even though these may have been introduced to reduce discrimination at work, or to mitigate against problematic workplace circumstances, they are nevertheless a "softer" form of protection and thus their efficacy depends on how seriously employees and supervisors take them, and the extent to which they may not be uniformly interpreted and applied throughout all parts of the same organization ${ }^{37}$. This was seen in our study where labor-management contracts with discrimination protections, were found to be associated with two times higher odds of outness at work. Studies have shown that organizations, with enacted workplace protections, also enjoy higher outness levels in LGBTI employees ${ }^{22}$, which is consistent with our findings. Also, it is important to note that our study focused on measures specifically targeting discrimination against sexual and/or gender minorities. Non-discriminatory measures that are not specifically focusing on LGBTI discrimination might not achieve the same results. The difference may also be explained by the 
top-down nature of guidelines, as opposed to horizontal impact of anti-discrimination contracts.

While our Austria-based LGBTI sample predominantly consists of gay men, one of the strengths of the study include a large sample of bisexual and transgender individuals, who are more commonly underrepresented in this type of research. To our knowledge, this is one of the largest samples of LGBTI individuals focusing on workplace outness, and the first study exploring these issues in a central European context. Further, the use of an extensive questionnaire covering different areas of workplace characteristics provides a robust and indepth picture of the experiences of LGBTI workers. This study was open to workers from a variety of occupational sectors and workplace sizes, further underpinning the variety of workbased experiences captured. However, our study results need to be viewed in light of some inherent limitations. An important limitation was the recruitment strategy with self-selection of the study participants. Data collection occurred online, which might have led to overrepresentation of younger, more educated, urban and affluent participants, causing an overestimation of outness at work. Furthermore, the questionnaire was propagated through personal contacts of already recruited individuals, which might have further contributed to the selection bias by oversampling similar participants. For the purposes of our analysis, our characterization of outness at work was dichotomized via a median split, which can be argued dilutes inherent sample heterogeneity and inevitably this prevented us from stratifying degrees of outness (and related characteristics) among respondents. This may lead to an overrepresentation of risk as indicated by the odds ratio. However, recent evidence does provide a defense of this analytical technique ${ }^{38}$. Further, outness as a construct is multifarious and non-uniformly described in the literature with a range of antecedents and individual consequences. Even though a worker was considered out, their disclosure might not have had an impact on the way they were perceived by their employer or their perceptions of their 
workplace. Indeed, in our analysis happiness at work and happiness with life did not predict employee outness which may, in part, be attributable to workplace happiness being understood by respondents as reflecting their own workplace self-efficacy and career development opportunities. As this is the first such analysis in an Austrian context to our knowledge, this study provides a useful benchmark for future, more nuanced assessments of this issue. Also, discrimination often starts before employment, with LGBTI individuals facing employment issues due to their identity ${ }^{39}$. It could therefore be that an a priori selection occurred, where LGBTI employees from organizations already providing a friendly workplace environment were more likely to respond. The sample consisted mostly of middle-aged employees. Considering the rapid development of legislative protections of LGBTI individuals in general, younger individuals may have had more protections than their older counterparts ${ }^{1}$. Moreover, social attitudes are rapidly improving across countries ${ }^{4}$, with rising numbers of young people being open about their identity at school and at work ${ }^{3}$. Increased visibility and decreased stigma of younger LGBTI workers might translate to a more accepting workplace culture. Moreover, given the low representation of trans and intersex participants in our study we were unable to investigate the specific aspects of their experiences. The overall lack of literature on the experiences of trans workers has been noted ${ }^{36}$.

This study employed a cross-sectional design, making it impossible to investigate causal links between workplace characteristics and outness, with a probability of reverse causation that cannot be definitively excluded. For example, , important associations were found that require further exploration in longitudinal designs. Finally, an intersectional approach would be needed to identify specific challenges faced by the various LGBTI subgroups ${ }^{40}$. Taking into account the interplay of participants' sociodemographic, workplace, and identity characteristics in a longitudinal study design might provide further insights into 
how to increase visibility and provide support for the most marginalized members of the workforce, in a rapidly changing societal and legal climate.

\section{Conclusions and relevance}

In our study on 1177 participants, we found that $52 \%$ of LGBTI participants were out at the workplace. Our analysis showed that participants who identified as bisexual and those living alone had the lowest levels of outness, and those enjoying longer duration of employment and binding internal non-discrimination contracts had the higher odds of being out at the workplace. In terms of managerial workplace intervention, we saw that more elaborate labor management contracts of non-discrimination were found to be associated with higher odds of outness at work. An overall accepting workplace culture was also associated with higher odds of workplace outness. Changes in these workplace characteristics would increase visibility of LGBTI workers and lead to a better promotion of diversity in the workplace.

\section{Statements}

\section{a. Contributorship}

L.M., I.G. conceived the study and did a formal analysis. D.S. and M.Z. data curation. L.M. original manuscript draft. All authors made considerable contributions in the final manuscript draft and approved it for submission.

\section{b. Funding}

This secondary analysis did not receive any third-party funding. Data collection and primary analysis were financed by the Vienna Chamber of Labour, who had no involvement with this analysis, its interpretation, or manuscript preparation. Funding number - Not Applicable. 
c. Competing interests

The authors declare no conflict of interest.

d. Data Sharing/Data availability

Data will be available upon reasonable request from the corresponding author.

e. Ethics Approval Statement (Applicable for Research/Original Articles)

This is a secondary analysis of previously gathered and available data. The study protocol was approved by the Vienna Chamber of Labour. Ethics approval number - Not Applicable. 
Table 1. Sociodemographic and work-related characteristics of the study population stratified by outness status

\begin{tabular}{|c|c|c|c|c|}
\hline Variable \% (n) & Total & Out & Not out & $\mathbf{p}$ \\
\hline & $\begin{array}{l}100 \% \\
(\mathrm{~N}=1177)\end{array}$ & $51.66 \%(608)$ & $48.34 \%(569)$ & \\
\hline \multicolumn{4}{|l|}{ Sexual and gender identity } & $<0.001$ \\
\hline Gay men & $40.0 \%(471)$ & $44.1 \%(268)$ & $35.7 \%(203)$ & \\
\hline Lesbian women & $28.6 \%(337)$ & $28.9 \%(176)$ & $28.3 \%(161)$ & \\
\hline Bisexual men/women & $18.8 \%(221)$ & $13.5 \%(82)$ & $24.4 \%(139)$ & \\
\hline Trans* and Intersex people & $7.5 \%(88)$ & $9.7 \%(59)$ & $5.1 \%(29)$ & \\
\hline Other sexual and gender identity & $5.1 \%(60)$ & $3.8 \%(23)$ & $6.5 \%(37)$ & \\
\hline \multicolumn{4}{|l|}{ Age } & $<0.001$ \\
\hline $16-25$ & $15.5 \%(182)$ & $12.3 \%(75)$ & $18.8 \%(107)$ & \\
\hline $26-35$ & $39.1 \%(460)$ & $33.7 \%(205)$ & $44.8 \%(255)$ & \\
\hline $36-50$ & $35.4 \%(417)$ & $42.4 \%(258)$ & $27.9 \%(159)$ & \\
\hline $51-65$ & $10.0 \%(118)$ & $11.5 \%(70)$ & $8.4 \%(48)$ & \\
\hline \multicolumn{4}{|l|}{ Austrian citizenship } & 0.280 \\
\hline Yes & $70.6 \%(831)$ & $69.6 \%(423)$ & $71.7 \%(408)$ & \\
\hline No & $8.2 \%(97)$ & $9.0 \%(55)$ & $7.4 \%(42)$ & \\
\hline \multicolumn{4}{|l|}{ Migration background } & 0.021 \\
\hline Yes & $22.9 \%(270)$ & $25.5 \%(155)$ & $20.2 \%(115)$ & \\
\hline No & $55.9 \%(658)$ & $53.1 \%(323)$ & $58.9 \%(335)$ & \\
\hline \multicolumn{4}{|l|}{ Education } & 0.081 \\
\hline Primary / vocational (ISCED 2-3) & $13.9 \%(164)$ & $15.8 \%(96)$ & $12.0 \%(68)$ & \\
\hline Secondary (ISCED 4-5) & $21.1 \%(248)$ & $20.9 \%(127)$ & $21.3 \%(121)$ & \\
\hline Tertiary (ISCED 6-8) & $43.9 \%(517)$ & $42.1 \%(256)$ & $45.9 \%(261)$ & \\
\hline \multicolumn{4}{|l|}{ Living situation } & $<0.001$ \\
\hline Alone & $26.9 \%(317)$ & $23.0 \%(140)$ & $31.1 \%(177)$ & \\
\hline With partner & $35.9 \%(422)$ & $40.5 \%(246)$ & $30.9 \%(176)$ & \\
\hline With partner and child(ren) & $4.2 \%(50)$ & $5.6 \%(34)$ & $2.8 \%(16)$ & \\
\hline $\begin{array}{l}\text { Other (flat sharing, with parents, } \\
\text { etc.) }\end{array}$ & $11.6 \%(137)$ & $9.4 \%(57)$ & $14.1 \%(80)$ & \\
\hline \multicolumn{4}{|l|}{ Urbanisation } & 0.626 \\
\hline Cities (densely populated) & $53.8 \%(633)$ & $53.0 \%(322)$ & $54.7 \%(311)$ & \\
\hline Towns and suburbs (intermediate) & $10.3 \%(121)$ & $11.0 \%(67)$ & $9.5 \%(54)$ & \\
\hline Rural areas (thinly populated) & $11.0 \%(130)$ & $10.7 \%(65)$ & $11.4 \%(65)$ & \\
\hline \multicolumn{4}{|l|}{ Employment status } & 0.433 \\
\hline$>35 \mathrm{~h} /$ week (full time) & $63.9 \%(752)$ & $62.8 \%(382)$ & $65.0 \%(370)$ & \\
\hline$<35 \mathrm{~h} /$ week (part time) & $36.1 \%(425)$ & $37.2 \%(226)$ & $35.0 \%(199)$ & \\
\hline \multicolumn{4}{|l|}{ Managing responsibility } & $<0.001$ \\
\hline No & $81.6 \%(960)$ & $468(77.0 \%)$ & $86.5 \%(492)$ & \\
\hline Yes & $18.4 \%(216)$ & $139(22.9 \%)$ & $13.5 \%(77)$ & \\
\hline \multicolumn{4}{|l|}{ Monthly income (after tax) } & 0.01 \\
\hline up to 1000 EUR & $14.2 \%(167)$ & $12.0 \%(73)$ & $16.5 \%(94)$ & \\
\hline
\end{tabular}




\begin{tabular}{|c|c|c|c|c|}
\hline up to 2000 EUR & $44.3 \%(521)$ & $44.2 \%(269)$ & $44.3 \%(252)$ & \\
\hline up to 3000 EUR & $29.8 \%(351)$ & $30.1 \%(183)$ & $29.5 \%(168)$ & \\
\hline more than 3000 EUR & $9.4 \%(111)$ & $11.5 \%(70)$ & $7.2 \%(41)$ & \\
\hline \multicolumn{4}{|l|}{ Company size } & 0.003 \\
\hline 1-10 employees & $20.6 \%(242)$ & $22.7 \%(138)$ & $18.3 \%(104)$ & \\
\hline 11-50 employees & $26.8 \%(315)$ & $26.8 \%(163)$ & $26.7 \%(152)$ & \\
\hline 51-250 employees & $20.6 \%(242)$ & $18.1 \%(110)$ & $23.2 \%(132)$ & \\
\hline 251 and more employees & $26.4 \%(311)$ & $23.2 \%(141)$ & $29.9 \%(170)$ & \\
\hline \multicolumn{4}{|c|}{ Duration of employment at current workplace } & $<0.001$ \\
\hline Up to 3 years & $44.3 \%(521)$ & $35.9 \%(218)$ & $53.3 \%(303)$ & \\
\hline $4-10$ years & $32.7 \%(385)$ & $34.2 \%(208)$ & $31.1 \%(177)$ & \\
\hline more than 10 years & $22.9 \%(269)$ & $29.6 \%(180)$ & $15.6 \%(89)$ & \\
\hline Perceived job stability, mean (SD) & $3.15(0.69)$ & $3.21(0.68)$ & $3.10(0.69)$ & 0.006 \\
\hline $\begin{array}{lll}\text { Perceived workplace } & \text { LGBTI } \\
\text { friendliness, } & \text { mean (SD) } & \\
\end{array}$ & $5.14(1.45)$ & $5.69(1.28)$ & $4.58(1.40)$ & $<0.001$ \\
\hline Happiness in life, mean (SD) & $3.24(0.74)$ & $3.34(0.72)$ & $3.12(0.74)$ & $<0.001$ \\
\hline Happiness at work, mean (SD) & $3.21(0.88)$ & $3.31(0.87)$ & $3.11(0.88)$ & 0.001 \\
\hline \multicolumn{4}{|l|}{ LGBTI coworkers } & $<0.001$ \\
\hline Present & $56.5 \%(665)$ & $60.7 \%(369)$ & $52.0 \%(296)$ & \\
\hline Not present & $34.4 \%(405)$ & $27.6 \%(168)$ & $41.7 \%(237)$ & \\
\hline \multicolumn{4}{|l|}{ LGBTI superiors } & $<0.001$ \\
\hline Present & $21.0 \%(247)$ & $26.8 \%(163)$ & $14.8 \%(84)$ & \\
\hline Not present & $69.2 \%(814)$ & $60.9 \%(370)$ & $78.0 \%(444)$ & \\
\hline \multicolumn{4}{|l|}{ Anti-discrimination guidelines } & 0.144 \\
\hline Present & $24.6 \%(290)$ & $25.7 \%(156)$ & $23.6 \%(134)$ & \\
\hline Not present & $65.3 \%(769)$ & $61.7 \%(375)$ & $69.2 \%(394)$ & \\
\hline \multicolumn{4}{|l|}{ Diversity representative } & 0.408 \\
\hline Present & $25.6 \%(301)$ & $25.8 \%(157)$ & $25.3 \%(144)$ & \\
\hline Not present & $64.4 \%(758)$ & $61.5 \%(374)$ & $67.5 \%(384)$ & \\
\hline \multicolumn{4}{|c|}{ Labor-management anti-discrimination contract } & 0.008 \\
\hline Present & $31.8 \%(374)$ & $34.2 \%(208)$ & $29.2 \%(166)$ & \\
\hline Not present & $58.2 \%(685)$ & $53.1 \%(323)$ & $63.6 \%(362)$ & \\
\hline \multicolumn{4}{|l|}{ Targeted diversity management } & 0.031 \\
\hline Present & $16.8 \%(198)$ & $18.6 \%(113)$ & $14.9 \%(85)$ & \\
\hline Not present & $73.2 \%(861)$ & $68.8 \%(418)$ & $77.9 \%(443)$ & \\
\hline \multicolumn{4}{|c|}{ Work council protections on LGBTI matters (if work council present) } & $<0.001$ \\
\hline Present & $25.5 \%(300)$ & $27.6 \%(168)$ & $23.2 \%(132)$ & \\
\hline Not present & $31.9 \%(376)$ & $24.2 \%(147)$ & $40.2 \%(229)$ & \\
\hline
\end{tabular}


Table 2. Variables associated with outness status at work. All variables with a $p<0.2$ in the univariate analysis were added to the model and are listed below. All variables were entered into the model simultaneously.

\begin{tabular}{|c|c|c|c|}
\hline Variable & OR & $95 \% \mathrm{CI}$ & $\mathbf{p}$ \\
\hline \multicolumn{4}{|l|}{ Sexual and gender identity (Ref: Gay men) } \\
\hline Lesbian women & 0.87 & $0.54-1.42$ & 0.585 \\
\hline Bisexual men/women & 0.46 & $0.27-0.81$ & 0.007 \\
\hline Trans* and Intersex people & 1.33 & $0.51-3.50$ & 0.561 \\
\hline Other sexual and gender identity & 0.27 & $0.06-1.16$ & 0.079 \\
\hline \multicolumn{4}{|l|}{ Age (Ref: 26-35) } \\
\hline $16-25$ & 1.33 & $0.63-2.84$ & 0.456 \\
\hline $36-50$ & 1.74 & $1.07-2.85$ & 0.027 \\
\hline $51-65$ & 1.36 & $0.64-2.88$ & 0.426 \\
\hline With managing responsibility & 1.10 & $0.64-1.90$ & 0.721 \\
\hline \multicolumn{4}{|l|}{ Monthly income (Ref: up to 2000 EUR) } \\
\hline up to 1000 EUR & 0.70 & $0.28-1.75$ & 0.445 \\
\hline up to 3000 EUR & 0.86 & $0.54-1.37$ & 0.523 \\
\hline more than 3000 EUR & 0.57 & $0.27-1.22$ & 0.145 \\
\hline \multicolumn{4}{|l|}{ Company size (Ref: 11-50 employees) } \\
\hline 1-10 employees & 1.22 & $0.57-2.61$ & 0.601 \\
\hline 51-250 employees & 1.27 & $0.73-2.23$ & 0.401 \\
\hline 251 and more employees & 0.83 & $0.49-1.41$ & 0.485 \\
\hline \multicolumn{4}{|c|}{ Duration of employment at current workplace (Ref: Up to 3 years) } \\
\hline 4-10 years & 1.26 & $0.77-2.06$ & 0.355 \\
\hline more than 10 years & 2.03 & $1.08-3.81$ & 0.027 \\
\hline Perceived job stability & 0.84 & $0.62-1.15$ & 0.289 \\
\hline Perceived workplace LGBTI friendliness & 1.61 & $1.36-1.91$ & $<0.001$ \\
\hline LGBTI coworkers not present & 0.73 & $0.45-1.19$ & 0.202 \\
\hline LGBTI superiors present & 1.57 & $0.97-2.54$ & 0.068 \\
\hline Anti-discrimination guidelines present & 0.53 & $0.32-0.90$ & 0.018 \\
\hline Labor-management anti-discrimination contract present & 2.02 & $1.23-3.32$ & 0.005 \\
\hline Targeted diversity management present & 0.96 & $0.57-1.61$ & 0.880 \\
\hline Work council protections present & 1.56 & $1.04-2.36$ & 0.033 \\
\hline Happiness in life & 1.03 & $0.75-1.40$ & 0.877 \\
\hline Happiness at work & 1.18 & $0.92-1.52$ & 0.203 \\
\hline With migration background & 1.52 & $0.96-2.39$ & 0.073 \\
\hline \multicolumn{4}{|l|}{ Education (Ref: Tertiary. ISCED 6-8) } \\
\hline Primary and vocational. ISCED 2-3 & 1.63 & $0.91-2.91$ & 0.102 \\
\hline Secondary. ISCED 4-5 & 0.99 & $0.61-1.62$ & 0.969 \\
\hline \multicolumn{4}{|l|}{ Living situation (Ref: With partner) } \\
\hline Alone & 0.50 & $0.32-0.79$ & 0.003 \\
\hline With partner and child(ren) & 1.57 & $0.59-4.18$ & 0.365 \\
\hline Other (flat sharing. with parents. etc.) & 0.49 & $0.25-0.96$ & 0.039 \\
\hline
\end{tabular}




\section{References}

1. Pew Research Center. A survey of LGBT Americans. Attitudes, Experiences and Values in Changing Times Washington, D.C.: Pew Research Center; 2013 [updated 2013/06/13/. Available from: https://www.pewsocialtrends.org/wpcontent/uploads/sites/3/2013/06/SDT_LGBT-Americans_06-2013.pdf accessed $13 / 12 / 20202020$.

2. Kent NO, Poushter J. The Global Divide on Homosexuality Persists: Pew Research Center, 2020:27.

3. Fundamental Rights Agency. A long way to go for LGBTI equality: European Union Agency for Fundamental Rights, 2020:72.

4. European Commission. Discrimination in the European Union. Special Eurobarometer. Brussels, Belgium, 2019.

5. Priola V, Lasio D, De Simone S, et al. The Sound of Silence. Lesbian, Gay, Bisexual and Transgender Discrimination in 'Inclusive Organizations': The Sound of Silence. Brit J Manage 2014;25(3):488-502. doi: 10.1111/1467-8551.12043

6. Resnick CA, Galupo MP. Assessing Experiences With LGBT Microaggressions in the Workplace: Development and Validation of the Microaggression Experiences at Work Scale. J Homosex 2019;66(10):1380-403. doi:

$10.1080 / 00918369.2018 .1542207$

7. Bauer GR, Hammond R, Travers R, et al. "I Don't Think This Is Theoretical; This Is Our Lives": How Erasure Impacts Health Care for Transgender People. J Assoc Nurses AIDS Care 2009;20(5):348-61. doi: 10.1016/j.jana.2009.07.004 
8. Einarsdóttir A, Hoel H, Lewis D. Fitting the bill? (Dis)embodied disclosure of sexual identities in the workplace. Work, Employment and Society 2016;30(3):489-505. doi: $10.1177 / 0950017014568136$

9. Bachmann CL, Gooch B. LGBT in Britain - Work Report, 2018.

10. Dewaele A, Van Houtte M, Buysse A, et al. What Predicts Visibility Management at Work? A Study of Gay, Lesbian, and Bisexual Flemish Government Employees. PSYCHOL BELG 2019;59(1):78. doi: 10.5334/pb.443

11. Brenner BR, Lyons HZ, Fassinger RE. Can Heterosexism Harm Organizations? Predicting the Perceived Organizational Citizenship Behaviors of Gay and Lesbian Employees. Career Dev Q 2010;58(4):321-35. doi: 10.1002/j.21610045.2010.tb00181.x

12. Lyons HZ, Brenner BR, Fassinger RE. A Multicultural Test of the Theory of Work Adjustment: Investigating the Role of Heterosexism and Fit Perceptions in the Job Satisfaction of Lesbian, Gay, and Bisexual Employees. J Couns Psychol 2005;52(4):537-48. doi: 10.1037/0022-0167.52.4.537

13. Parnell MK, Lease SH, Green ML. Perceived Career Barriers for Gay, Lesbian, and Bisexual Individuals. J Career Dev 2012;39(3):248-68. doi: $10.1177 / 0894845310386730$

14. Riggle EDB, Rostosky SS, Black WW, et al. Outness, concealment, and authenticity: Associations with LGB individuals' psychological distress and well-being. Psychol Sex Orientat Gend Divers 2017;4(1):54-62. doi: 10.1037/sgd0000202

15. Waldo CR. Working in a majority context: A structural model of heterosexism as minority stress in the workplace. J Couns Psychol 1999;46(2):218-32. doi: $10.1037 / 0022-0167.46 .2 .218$ 
16. Fundamental Rights Agency. European Union lesbian, gay, bisexual and transgender survey: results at a glance, 2013.

17. Badgett MVL, Durso LE, Kastanis A, et al. The Business Impact of LGBT-Supportive Workplace Policies: UCLA: The Williams Institute; 2013 [Available from: https://escholarship.org/uc/item/3vt6t9zx accessed 14.12. 2020.

18. Everly BA, Shih MJ, Ho GC. Don't ask, don't tell? Does disclosure of gay identity affect partner performance? J Exp Soc Psychol 2012;48(1):407-10. doi: 10.1016/j.jesp.2011.08.005

19. Studies IfH. Queer in Wien: Stadt Wien Studie zur Lebenssituation von Lesben, Schwulen, Bisexuellen, Transgender und Intersex Personen (LGBTIs). Vienna, 2015.

20. McFadden C. Lesbian, Gay, Bisexual, and Transgender Careers and Human Resource Development: A Systematic Literature Review. Hum Resource Dev Rev 2015;14(2):125-62. doi: 10.1177/1534484314549456

21. Hossain M, Atif M, Ahmed A, et al. Do LGBT Workplace Diversity Policies Create Value for Firms? J Bus Ethics 2020;167:775-91. doi: 10.1007/s10551-019-04158-z

22. Rostosky SS, Riggle EDB. "Out" at work: The relation of actor and partner workplace policy and internalized homophobia to disclosure status. J Couns Psychol 2002;49(4):411-19. doi: 10.1037/0022-0167.49.4.411

23. Webster JR, Adams GA, Maranto CL, et al. Workplace contextual supports for LGBT employees: A review, meta-analysis, and agenda for future research. Hum Resour Manage 2018;57(1):193-210. doi: 10.1002/hrm.21873

24. Bursac Z, Gauss CH, Williams DK, et al. Purposeful selection of variables in logistic regression. Source Code Biol Med 2008;3(1):17. doi: 10.1186/1751-0473-3-17 
25. Lloren A, Parini L. How LGBT-Supportive Workplace Policies Shape the Experience of Lesbian, Gay Men, and Bisexual Employees. Sex Res Soc Policy 2017;14(3):289-99. doi: $10.1007 / \mathrm{s} 13178-016-0253-\mathrm{x}$

26. Bell MP, Özbilgin MF, Beauregard TA, et al. Voice, silence, and diversity in 21st century organizations: Strategies for inclusion of gay, lesbian, bisexual, and transgender employees. Hum Resour Manage 2011;50(1):131-46. doi: 10.1002/hrm.20401

27. Hoang M, Holloway J, Mendoza RH. An Empirical Study into the Relationship between Bisexual Identity Congruence, Internalized Biphobia and Infidelity among Bisexual Women. J Bisex 2011;11(1):23-38. doi: 10.1080/15299716.2011.545285

28. Barker M, Richards C, Jones R, et al. The bisexuality report: Bisexual inclusion in LGBT equality and diversity: Milton Keynes, UK: Centre for Citizenship, Identities and Governance, Faculty of Health and Social Care, The Open University, 2012.

29. Köllen T. Bisexuality and Diversity Management—Addressing the B in LGBT as a Relevant 'Sexual Orientation' in the Workplace. J Bisex 2013;13(1):122-37. doi: $10.1080 / 15299716.2013 .755728$

30. Zivony A, Lobel T. The Invisible Stereotypes of Bisexual Men. Arch Sex Behav 2014;43(6):1165-76. doi: 10.1007/s 10508-014-0263-9

31. Yost MR, Thomas GD. Gender and Binegativity: Men's and Women's Attitudes Toward Male and Female Bisexuals. Arch Sex Behav 2012;41(3):691-702. doi: $10.1007 / \mathrm{s} 10508-011-9767-8$

32. Arriaga AS, Parent MC. Partners and prejudice: Bisexual partner gender and experiences of binegativity from heterosexual, lesbian, and gay people. Psychol Sex Orientat Gend Divers 2019;6(3):382-91. doi: 10.1037/sgd0000337 
33. Green HB, Payne NR, Green J. Working Bi: Preliminary Findings from a Survey on Workplace Experiences of Bisexual People. J Bisex 2011;11(2-3):300-16. doi: $10.1080 / 15299716.2011 .572007$

34. Brewster ME, Velez B, DeBlaere C, et al. Transgender individuals' workplace experiences: The applicability of sexual minority measures and models. J Couns Psychol 2012;59(1):60-70. doi: 10.1037/a0025206

35. Sangganjanavanich VF, Headley JA. Facilitating Career Development Concerns of Gender Transitioning Individuals: Professional Standards and Competencies. Career Dev $Q$ 2013;61(4):354-66. doi: 10.1002/j.2161-0045.2013.00061.x

36. Law CL, Martinez LR, Ruggs EN, et al. Trans-parency in the workplace: How the experiences of transsexual employees can be improved. $J$ Vocat Behav 2011;79(3):710-23. doi: 10.1016/j.jvb.2011.03.018

37. Ragins BR, Singh R, Cornwell JM. Making the invisible visible: Fear and disclosure of sexual orientation at work. J Appl Psychol 2007;92(4):1103-18. doi: 10.1037/00219010.92.4.1103

38. Iacobucci D, Posavac SS, Kardes FR, et al. Toward a more nuanced understanding of the statistical properties of a median split. Journal of Consumer Psychology 2015;25(4):652-65. doi: https://doi.org/10.1016/j.jcps.2014.12.002

39. Sears B, Mallory C. Employment Discrimination against LGBT People: UCLA: The Williams Institute 2014.

40. McGarrity LA. Socioeconomic status as context for minority stress and health disparities among lesbian, gay, and bisexual individuals. Psychol Sex Orientat Gend Divers 2014;1(4):383-97. doi: 10.1037/sgd0000067 